\title{
Susceptibility of Hop Cultivars and Rootstock to Downy Mildew Caused by Pseudoperonospora humuli
}

\author{
Douglas S. Higgins and Mary K. Hausbeck \\ Department of Plant, Soil and Microbial Sciences, Michigan State \\ University, East Lansing, MI 48824
}

Additional index words. 'Cascade', 'Centennial', 'Comet', 'Columbia', eastern United States, Humulus lupulus, 'Newport', 'Nugget', Rhizomes, 'Tahoma', 'Triple Pearl'

\begin{abstract}
Annual downy mildew [Pseudoperonospora humuli (Miyabe \& Takah.) G.W. Wilson, (1914)] epidemics threaten hop (Humulus lupulus L. var. lupulus) production throughout the eastern United States. Rootstock rot complicates foliar disease assessments because dormant buds may rot before producing a symptomatic basal shoot and noncolonized buds produce healthy shoots. We selected 12 cultivars to evaluate downy mildew susceptibility (2016 and 2017) and examined the rhizomes of a subset of six cultivars (2018) that showed clear differences in foliar disease ratings to determine rootstock rot susceptibility. Trials were conducted on nontrellised hop yards established at two research farms in $\mathbf{2 0 1 6}$ and managed without fungicides. The relative area under the disease progress curve (rAUDPC) values for foliar disease severity and density ratings were consistently higher for 'Cascade', 'Centennial', and 'Nugget' than for 'Newport', 'Tahoma', and 'Columbia'. Only 'Centennial' had a higher wetrot cortex discoloration $(C D)$ incidence $(71.5 \%)$ and severity $(31.9 \%)$ in its rhizomes than the other cultivars. Among cultivars with low foliar disease levels, Columbia was less vigorous (shoots/plant) than 'Tahoma', but had similar wet-rot CD (incidence, $46.4 \%$ to $47.2 \%$; severity, $12.5 \%$ to $17.7 \%$ ). The levels of wet-rot CD for 'Tahoma', 'Newport', and 'Columbia' were comparable to those of some cultivars with more severe foliar disease symptoms ('Nugget' and 'Cascade'). Differences in foliar disease among cultivars with similar levels of rootstock rot suggest a resistance defense mechanism to $P$. humuli. Additional work is needed to clarify rootstock infection sites and characterize defense responses to aid future breeding efforts.
\end{abstract}

Niche hop (Humulus lupulus L. var. lupulus) production occurs throughout the eastern United States (George, 2020). However, the wet and humid environment of these regions incite annual epidemics of downy mildew (DM) [Pseudoperonospora humuli (Miyabe \& Takah.) G.W. Wilson, (1914)] that limit production (O'Neal, 2015). DM is a chronic systemic disease that rots and weakens hop rootstock (perennial underground stem

Received for publication 16 Nov. 2020. Accepted for publication 14 Feb. 2021

Published online 29 April 2021.

This research is based on work supported by the Michigan State University (MSU) Project GREEEN Grant Award Numbers GR15-021 and GR17-022, Specialty Crop Block Grant Program Agreement Number 791AgDSC1805, the MSU SWMREC Award, and MSU AgBioReserach. We thank Z. Hayden for advice about agronomic practices, M. Nelson for recommending the nontrellised field design, and F. Couto Alves for help with the statistical analysis. We thank L. Espinoso for assistance with extracting and processing rhizomes. We also thank the Michigan Hop Growers for their support and help selecting cultivars for this study.

M.K.H. is the corresponding author. E-mail: hausbec1@msu.edu.

This is an open access article distributed under the CC BY-NC-ND license (https://creativecommons. org/licenses/by-nc-nd/4.0/) organs, crown, and accompanying roots), thereby depleting winter carbohydrate reserves needed for vigorous perennial growth (Williams et al., 1961) and reducing yield up $56.2 \%$ (Coley-Smith, 1962). Hypertrophic apical buds cease to develop, thus necessitating additional labor costs to retrain replacement bines (Ware, 1926). Direct yield and quality loss occur when infected inflorescences abort, develop discolored bracts, and lose alpha-acids (Neve, 1991; Royle and Kremheller, 1981).

DM is incited by a polycyclic airborne pathogen that overwinters primarily in the rootstock (Coley-Smith, 1962; Johnson and Skotland, 1985; Skotland, 1961; Ware, 1926). The pathogen can colonize rootstock from infections that occur at the tip and base of a shoot (Coley-Smith, 1962, 1965; Ware, 1926; Williams et al., 1961). Zoosporangia can infect storage roots directly (ColeySmith, 1965); however, the infection process is unknown. DM symptoms in rootstock include red-brown to dark brown and black wet rot that can appear as water-soaked flecks and streaks; however, DM is more often observed as large discolored areas in the cortex tissue (Coley-Smith, 1964; Skotland, 1961; Ware, 1926). Infected rootstock buds that are colonized give rise to symptomatic basal shoots with swollen stems, shortened internodes, and chlorotic downward cupped leaves
(Coley-Smith, 1962, 1964; Skotland, 1961; Ware, 1926). Sporangia develop primarily on abaxial leaf surfaces under high relative humidity (Johnson and Skotland, 1985) and are disseminated by wind and splashing water (Royle, 1970; Sonoda and Ogawa, 1972). Water triggers indirect infection by swimming zoosporangia that penetrate via stomata openings (Royle and Thomas, 1971a, 1971b, 1973). Symptomatic leaves that exhibit chlorotic lesions limited by the leaf vein are the result of secondary pathogen spread (Neve, 1991; Royle and Kremheller, 1981). Secondary shoot infections result in symptoms similar to basal shoots but are distinguishable by one or more normally elongated internodes at the shoot base (Coley-Smith, 1962; Skotland, 1961).

Breeding for resistance to DM in diploid, dioecious H. lupulus has received limited domestic attention (Neve, 1991) until recently (Henning et al., 2015, 2016, 2018; Woods and Gent, 2016). All hop cultivars appear to be susceptible to DM, but cultivars exhibiting low levels of disease are often considered "resistant" (Henning et al., 2018; Mahaffee et al., 2009; Woods and Gent, 2016). DM resistance in $H$. lupulus appears to be under quantitative genetic control by multiple loci (Henning et al., 2015). The registration of a DM-resistant male line (USDA 21087M) offers new crossing opportunities with DM-resistant female lines (Henning et al., 2018). Therefore, the identification of DM-resistant female lines adapted to local growing conditions is necessary (Henning et al., 2018; Woods and Gent, 2016).

An inverse relationship between crown rot susceptibility and the incidence of symptomatic primary shoots complicates field assessments of DM susceptibility (Neve, 1991; Woods and Gent, 2016). Cultivars highly susceptible to rootstock rot may not develop foliar disease symptoms (Coley-Smith, 1964; Neve, 1991; Woods and Gent, 2016). Dormant buds rapidly rot before producing symptomatic basal shoots, but noncolonized buds still produce healthy shoots (Neve, 1991). Although the rootstock of some susceptible hop cultivars succumbs to DM rot, others appear to tolerate infection and produce a mix of healthy and diseased shoots (Coley-Smith, 1962, 1964; Johnson and Anliker, 1985; Skotland, 1961; Woods and Gent, 2016). Woods and Gent (2016) proposed an indirect method to detect variations in susceptibility to rootstock rot by combining disease assessments of symptomatic DM shoots (incidence) with measurements of plant vigor (total number of shoots produced). High-vigor cultivars with shoots displaying minor DM symptoms were considered resistant. However, low-vigor cultivars are difficult to classify because their growth rate might be a result of rootstock rot susceptibility to DM or poor adaptation of the cultivar to its environment (Woods and Gent, 2016).

Local Michigan hop propagators offer 45 to 54 cultivars to regional growers. In some cases, highly desirable brewing characteristics 
may incentivize the planting of DM-susceptible cultivars (Erin Lizotte, personal communication). In conjunction with the statewide association, Hop Growers of Michigan, we selected 12 cultivars to evaluate DM susceptibility. We examined lateral growing rhizomes of a subset of six cultivars for DM symptoms. Cultivars were chosen based on differences in foliar DM susceptibility. Preliminary research results have been presented previously (Higgins and Hausbeck, 2017, 2018).

\section{Materials and Methods}

Field plots. Evaluations of nontrellised hop plants were performed at the Michigan State University (MSU) Southwest Michigan Research and Extension Center (SWM) in Benton Harbor, MI (lat. 42.6854 ${ }^{\circ}$, long. $-84.4716^{\circ}$ ), and replicated at the MSU Plant Pathology Farm (PPF) in Lansing, MI (lat. $42.0835^{\circ}$, long. $-86.3542^{\circ}$ ). Plots were established in 52.3-m rows of raised plant beds covered with black plastic and buried drip irrigation. All rows were spaced $2.4 \mathrm{~m}$ apart. Each treatment plot consisted of 10 plants in a row with $1.1 \mathrm{~m}$ between plants and a $0.8-\mathrm{m}$ walkway between plots. A single buffer row of nontreated 'Nugget' (Haunold et al., 1984) plants bordered each experiment. Hop plantlets propagated from softwood cuttings by a commercial propagator were transplanted on 3 June (PPF) and 6 June (SWM) 2016 and grown until rhizomes were destructively extracted in 2018. Hop shoots extending into the center aisles were periodically cut back with a mechanical hedge trimmer to a uniform distance outside of the rating area. Plots were drip-irrigated as necessary. Fertilizer was applied according to soil tests in 2016 and 2017 as a combination of granular fertilizer $6 \mathrm{~N}-24 \mathrm{P}-24 \mathrm{~K}$ and urea $46 \mathrm{~N}-0 \mathrm{P}-0 \mathrm{~K}$ before bed formation and MORA-LEAF Plus 20N-20P-20K with micronutrients (Wilbur-Ellis, San Francisco, CA), Liquid Re-Nforce K $5 \mathrm{~N}-0 \mathrm{P}-20 \mathrm{~K}$ with sulfur (Loveland Products, Inc., Greeley, CO), and urea $46 \mathrm{~N}-0 \mathrm{P}-0 \mathrm{~K}$ fertilizer dissolved in water and injected through the drip line. Weeds were managed through mechanical cultivation and fungicides were not applied.

Plots were inoculated in 2016 on 15, 22, and 28 June at PPF, and on 21 June and 8 July at SWM. Plots were artificially inoculated only in 2016. Inoculum was prepared from diseased shoots collected $24 \mathrm{~h}$ before inoculation from three commercial hop yards according to the methods described by Gent et al. (2008). Zoospore suspensions were strained through two layers of cheese cloth, added to $15.1 \mathrm{~L}$ of water, and injected into overhead mist irrigation using a $\mathrm{CO}_{2}$ pressurized container (Nelson and Grove, 2004). The concentration of zoospore suspension was $2.6 \times 10^{4}$ sporangia/mL for inoculations on 15 June (PPF) and $2.0 \times 10^{4}$ for inoculations on 21 June (SWM) and 22 June (PPF). Inoculum for inoculations on 28 June (PPF) and 7 July (SWM) was prepared from 60 to 80 diseased shoots, and $\approx 5.2 \times 10^{6}$ to $6.1 \times$ $10^{6}$ sporangia $/ \mathrm{mL}$ were injected into the overhead mist irrigation. Plots were misted in
2016 on $7,11,21$, and 23 July and 15 Aug. (SWM) and on 24 and 29 June and 11 July (PPF) to create extended durations of leaf wetness conducive to DM.

Treatments were arranged in a randomized complete block design with four replications. Treatments were the hop cultivars, including Tahoma, Fuggle H (U.S.), Mt. Rainier, Newport (Henning et al., 2004), Perle, Nugget (Haunold et al., 1984), Sorachi Ace, Cascade (Brooks et al., 1972), Columbia (Haunold et al., 1976), Triple Pearl, Centennial (Kenny and Zimmermann, 1991), and Comet (Zimmermann et al., 1975). In 2016, 'Fuggle H.', 'Sorachi Ace', and 'Mt. Rainier' were removed from the experiments because damage from two-spotted spidermites (Tetranychus urticae) at one or both locations in 2016 interfered with DM ratings. Subsequently, two-spotted spider mites and potato leaf hoppers (Empoasca fabae) were managed with applications of bifenazate, bifenthrin, fenazaquin, and imidacloprid. 'Perle' was also removed from the experiments in 2016 at both locations because it tested positive for Hop latent virus, Apple mosaic virus, and American hop latent virus.

Foliar disease ratings. In each plot, the inner 6 of the 10 plants per replication were assessed for foliar disease severity and density (2016 and 2017) and plant vigor (2017). If newly transplanted plants died before inoculation or did not overwinter for the 2017 assessment, one of the remaining four plants in the plot was assessed. When plants within each plot began to grow together, a frame $(1.2 \times 0.9 \mathrm{~m})$ constructed of PVC pipe $(1.3$ $\mathrm{cm})$ was placed over the center of each plant. The corners of the frame were marked in the plot with wooden stakes to ensure that subsequent measurements included the same area. Frames were used to rate all experiments from 18 Aug. (SWM) and 19 Aug. (PPF) in 2016 and from 29 May (SWM) and 7 June (PPF) in 2017. Disease severity, measured as a combination of symptomatic shoots and leaves, was estimated visually using the Horsfall-Barratt scale of 1 to 12 , where $1=0 \%$ plant area diseased, $2=>0 \%$ to $3 \%, 3=$ $>3 \%$ to $6 \%, 4=>6 \%$ to $12 \%, 5=>12 \%$ to $25 \%, 6=>25 \%$ to $50 \%, 7=>50 \%$ to $75 \%, 8=>75 \%$ to $87 \%, 9=>87 \%$ to $94 \%, 10=>94$ to $97 \%, 11=>97$ to $<100 \%$, and $12=100 \%$ plant area (Horsfall and Barratt, 1945). Before statistical analysis, rating values from the Horsfall-Barratt scale were converted to midpoint values. Disease density was determined by the number of symptomatic shoots per plant (Gent et al., 2012). Plant vigor was the average number of shoots per plant (Woods and Gent, 2016). In 2016, disease ratings were performed on 20 and 28 July, on 4, 11, 18, and 25 Aug., 1, 8, 15 , and 22 Sept., and 6 Oct. (SWM), and on 22 and 29 July, 5, 12, 19, and 26 Aug., 2, 9, 16, and 23 Sept., and 7 Oct. (PPF). In 2017, disease ratings were performed on 9, 16, 23, and 30 May, 6, 13, 20, 27, 11, 18, and 25 July, and 1 Aug. (SWM), and on 11, 18, and 24 May, 1, 8, 15, 22, and 29 June, 6, 13, 20, and 27 July, and 3 Aug. (PPF). Plant vigor ratings were obtained only during 2017 on 11,18 , and 24 May and 1, 8, 15, and 22 June (PPF), and on 9, 16, 23, and 30 May and 6, 13, and 20 June (SWM).

Data regarding disease severity and density were summarized for each treatment level by calculating the area under the disease progress curve (AUDPC) and then dividing the AUDPC by the time duration between the first and last disease rating date to determine the rAUDPC (Madden et al., 2007). A statistical analysis was performed using SAS software, version 9.4 (SAS Institute Inc., Cary, NC) with a three-factor linear mixed model to account for repeated measures between years. Year (2016 and 2017), location (PPF and SWM), cultivar, two-way (year $\times$ location; year $\times$ cultivar; location $\times$ cultivar $)$ interactions, and three-way (year $\times$ location $\times$ cultivar) interactions were considered fixed effects. Blocks nested in location and twoway and three-way interactions between blocks and fixed effects were considered random effects. A global analysis of variance (ANOVA) was conducted using PROC GLIMMIX. The SE and degrees of freedom correction were predicted using the Kenward and Roger option. Assumptions of normality and equal variances were confirmed with residual plots and the Levene's test, respectively. Data were transformed using the lambda value (severity, 0.65; density, 0.25) derived from a Box-Cox analysis (Box and Cox, 1964). The GLIMMIX procedure was adjusted to estimate the variances separately and account for variance heterogeneity. For simple effects, the SLICE option was used to perform the ANOVA separately for each factor and the SLICEDIFF option was used to make all possible pairwise differences among levels of one factor. Least-squared means comparisons were performed using Tukey's adjusted $P$ values. All transformed data were back-transformed for presentation in tables.

The statistical analysis of plant vigor was performed with a two-factor linear mixed model. Location and cultivar were fixed factors. Blocks were nested in location and considered a random factor. The GLIMMIX procedure was adjusted to estimate the variances separately and account for variance heterogeneity. Least-squared means comparisons were performed using Tukey's adjusted $P$ values. All transformed data were backtransformed for presentation in tables.

Rhizome disease ratings. In 2018, rhizomes were collected at PPF $(\mathrm{n}=590)$ from 20 June to 4 July and at SWM $(\mathrm{n}=411)$ from 30 July to 11 Aug. Rhizomes were extracted from the replicated plot of six hop cultivars (Nugget, Centennial, Cascade, Tahoma, Columbia and Newport) at each location. Rhizomes were extracted from the third, fifth, and seventh plants from each treatment plot. Rhizomes were exposed by flooding the plant with water from a garden hose or portable pressure washer. Up to 10 laterally growing rhizomes, identified by a pair of buds at regularly spaced internodes, were arbitrarily chosen from each plant. Rhizomes $\approx 14 \mathrm{~cm}$ in length were cut close to the attachment 
point of the crown with a sterile surgical blade. If a plant had fewer than 10 horizontal rhizomes, then the maximum number of horizontal rhizomes present was removed. If a plant was dead, then rhizomes from a neighboring plant were sampled. Plants in two 'Nugget' replicate plots at SWM were either completely dead or the plant growth was so
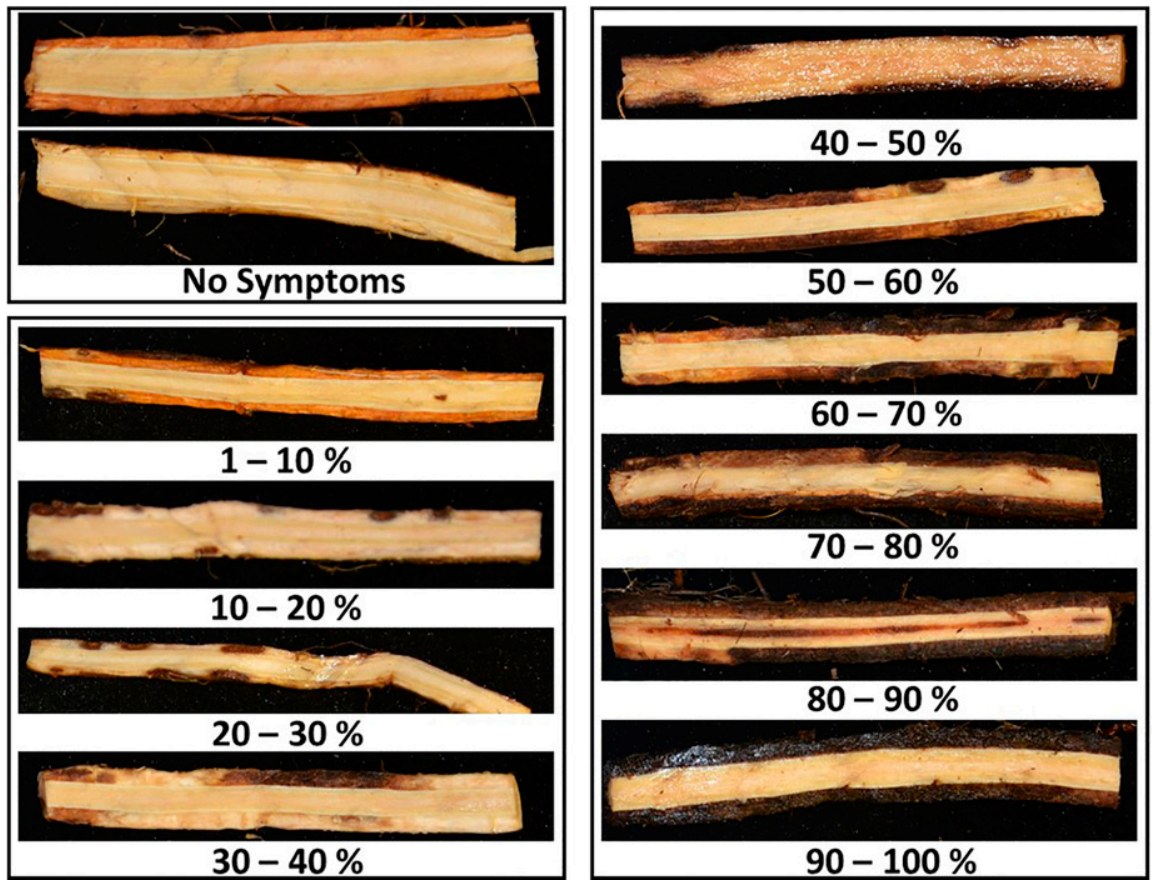

Fig. 1. Disease diagram developed to aid in the assessment of wet-rot cortex discoloration occurring in the rhizomes of hop cultivars. Rhizomes were split longitudinally with a sterile surgical blade. Disease severity was estimated directly $(0 \%$ to $100 \%)$ with the aid of this disease diagram as the portion of cortex tissue covered with wet rot discoloration.
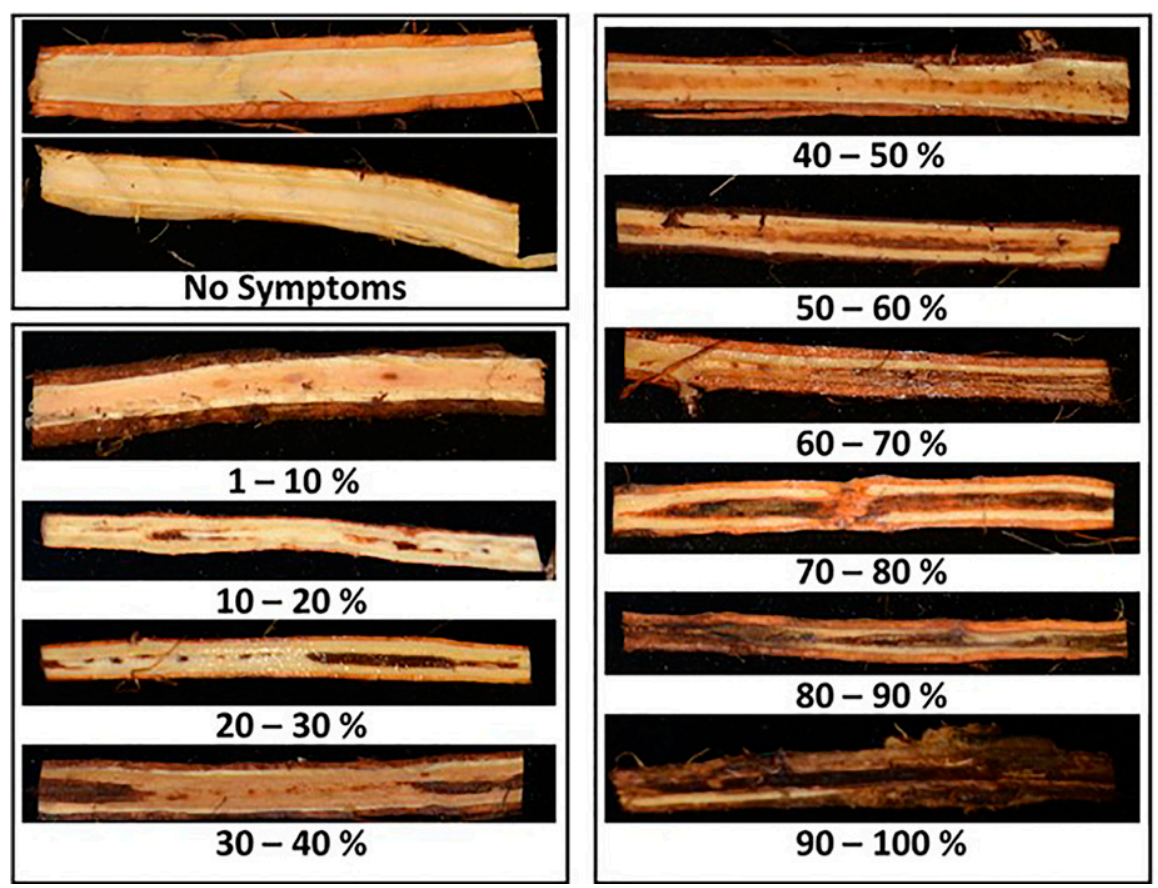

Fig. 2. Disease diagram developed to aid in the assessment of vascular/pith discoloration occurring in the rhizomes of hop cultivars. Rhizomes were split longitudinally with a sterile surgical blade. Disease severity was estimated directly $(0 \%$ to $100 \%)$ with the aid of this disease diagram as the portion of vascular/pith tissue covered with discoloration.
Rhizomes were washed with tap water and their diameters were recorded with a digital caliper (Husky, Atlanta, GA). Rhizomes were split longitudinally with a sterile surgical blade and evaluated for symptoms typically associated with DM. Disease incidence and severity were determined separately for wet-rot discoloration located in the cortex (cortex rot $=\mathrm{CD}$ ) or vascular or pith tissue (vascular/pith discoloration $=$ VPD). Disease incidence was determined by the number of symptomatic rhizomes from the total number of rhizomes. Disease severity was estimated directly $(0 \%$ to $100 \%)$ with the aid of a disease diagram (Figs. 1 and 2) as the portion of cortex tissue with wet-rot discoloration or vascular/pith tissue discoloration.

A statistical analysis was performed using a two-factor linear mixed model. Location (PPF and SWM) and cultivar were fixed factors. Blocks were nested in location and considered a random factor. The ANOVA was conducted using PROC GLIMMIX for the main effects of location and cultivar and the interaction between location and cultivar. The SE and degrees of freedom correction were predicted using the Kenward and Roger option. Assumptions of normality and equal variances were confirmed with residual plots and the Levene's test, respectively. Datasets for VPD incidence and severity and CD severity were square-root-transformed to meet assumptions; data for rhizome size were logtransformed and the GLIMMIX procedure was adjusted to estimate the variances separately and account for variance heterogeneity. Multiple comparisons of the main effects were performed to determine insignificant interactions $(P=0.05)$. Significant interactions were examined by cell means and comparisons among simple effects. Least-squared means comparisons were performed using Fisher's protected least significant differences. All transformed data were back-transformed for presentation in tables. Phenotypic correlations were estimated from the error caused by treatment effects of disease ratings and rhizome size.

\section{Results}

Foliar disease ratings. For disease severity, the three-way (year $\times$ location $\times$ cultivar) and two-way (location $\times$ cultivar) interactions were not significant (Table 1). The twoway interaction between year and cultivar was significant (Table 1), and the simple effects were analyzed based on cultivar (sliced test results not shown) and year (Table 2). Each cultivar had a significant treatment effect $(P \leq 0.0009)$ and lower disease severity rAUDPC values based on cultivar in 2017 than 2016. Significant treatment effects for disease severity (rAUDPC) were observed based on year in both 2016 and 2017 (Table 2). In 2016 and 2017, 'Centennial', 'Cascade', and 'Nugget' were among the most susceptible cultivars with high disease severity (rAUDPC) values. 'Columbia', 'Tahoma', and 'Newport' were among the least susceptible cultivars in 2016 and 2017, with significantly lower disease 
severity values than 'Centennial', 'Cascade', and 'Nugget'. Disease susceptibility was less clear for 'Triple Pearl' and 'Comet'. These cultivars had rAUDPC values (disease severity) that were significantly higher than those of cultivars Columbia, Tahoma, and Newport in 2017, but only Triple Pearl had a higher rAUDPC value than Newport in 2016.

For disease density, the three-way (year $\times$ location $\times$ cultivar) and two-way interaction (location $\times$ cultivar; location $\times$ year) were not significant (Table 1). The two-way interaction between year and cultivar was significant (Table 1), and the simple effects were analyzed based on cultivar (sliced test results not shown) and year (Table 2). Most cultivars had a significant treatment effect $(P \leq$ 0.0102 ) and lower disease density rAUDPC values based on cultivar in 2017 than 2016 . 'Comet' $(\mathrm{F}=0.26 ; P=0.6185)$ and 'Nugget' $(\mathrm{F}=3.95 ; P=0.0778)$ had similar rAUDPC values based on cultivar in both years. Significant treatment effects were observed based on year in both 2016 and 2017 (Table 2). In 2016 and 2017, 'Centennial', 'Cascade', and 'Nugget' were among the most susceptible cultivars with high disease density (rAUDPC) values. 'Columbia',

Table 1. Mixed model type III test of fixed effects for plant vigor and disease ratings for downy mildew (Pseudoperonospora humuli) foliar symptoms of hop (Humulus lupulus) cultivars.

\begin{tabular}{|c|c|c|c|c|}
\hline Response variable and effect $^{\mathrm{z}}$ & Num $\mathrm{DF}^{\mathrm{y}}$ & Den $\mathrm{DF}^{\mathrm{x}}$ & $F$ value & $\operatorname{Pr}>F$ \\
\hline \multicolumn{5}{|l|}{ Foliar disease severity } \\
\hline Year & 1 & 8.67 & 876.71 & $<0.0001$ \\
\hline Cultivar & 7 & 29.01 & 43.30 & $<0.0001$ \\
\hline Location & 1 & 6.28 & 100.61 & $<0.0001$ \\
\hline Year $\times$ cultivar & 7 & 17.16 & 12.93 & $<0.0001$ \\
\hline Year $\times$ location & 1 & 8.67 & 12.66 & 0.0065 \\
\hline Location $\times$ cultivar & 7 & 29.01 & 1.71 & 0.1467 \\
\hline Year $\times$ location $\times$ cultivar & 7 & 17.16 & 2.60 & 0.0504 \\
\hline \multicolumn{5}{|l|}{ Foliar disease density } \\
\hline Year & 1 & 51.09 & 178.07 & $<0.0001$ \\
\hline Cultivar & 7 & 31.79 & 53.82 & $<0.0001$ \\
\hline Location & 1 & 60.17 & 1.08 & 0.3033 \\
\hline Year $\times$ cultivar & 7 & 25.11 & 12.82 & $<0.0001$ \\
\hline Year $\times$ location & 1 & 51.09 & 0.32 & 0.5714 \\
\hline Location $\times$ cultivar & 7 & 31.79 & 0.94 & 0.4910 \\
\hline Year $\times$ location $\times$ cultivar & 7 & 25.11 & 0.73 & 0.6490 \\
\hline \multicolumn{5}{|l|}{ Plant vigor } \\
\hline Location & 1 & 14.45 & 0.20 & 0.6651 \\
\hline Cultivar & 7 & 12.94 & 21.98 & $<0.0001$ \\
\hline Location $\times$ cultivar & 7 & 12.94 & 3.69 & 0.0205 \\
\hline
\end{tabular}

${ }^{\mathrm{z}}$ Statistical analysis of foliar disease density and severity was performed using data from two locations during 2 years as a linear mixed model with unequal variances and repeated measures. Statistical analysis of plant vigor was performed using data from two locations as a linear mixed model with unequal variances.

${ }^{\mathrm{y}}$ Num DF 5 numerator degrees of freedom.

${ }^{\mathrm{x}}$ Den DF 5 denominator degrees of freedom.

'Tahoma', and 'Newport' were among the least susceptible cultivars in 2016 and 2017 , with significantly lower disease severity values than 'Centennial', 'Cascade', and 'Nugget'. The rAUDPC values for disease density of 'Triple Pearl' and 'Comet' were higher than those of 'Columbia', 'Tahoma', and 'Newport' only in 2017.

There was a significant interaction for mean plant vigor (shoots/plant) between location and cultivar (Table 1), and the simple effects were analyzed based on cultivar (sliced test results not shown) and location (Table 2). Most cultivars did not have significant treatment effects $(P>0.05)$, and plant vigor based on cultivar was similar at both locations, with a few exceptions. 'Cascade' ( $\mathrm{F}=$ 7.29; $P=0.0364)$ and 'Centennial' $(\mathrm{F}=$ $10.39 ; P=0.0182$ ) produced significantly more shoots by cultivar at PFF than at SWM. 'Newport' ( $\mathrm{F}=6.84 ; P=0.0434)$ produced less shoots at PFF than at SWM. Significant treatment effects were observed based on location at both PPF and SWM (Table 2). At PPF, the mean plant vigor of cultivars with consistently high foliar disease severity and density ('Cascade', 'Centennial', and 'Nugget') was comparable to that of 'Tahoma', a cultivar ranked significantly less susceptible in foliar disease ratings. The mean vigor (PPF) of 'Tahoma' was more than two-times higher than that of other cultivars with similar low foliar disease susceptibility ('Columbia' and 'Newport'). At SWM, trends in plant vigor were similar to those at PPF, with no differences in vigor between cultivars with high foliar disease ratings ('Cascade', 'Centennial', and 'Nugget') and the less susceptible 'Tahoma'. 'Tahoma' was significantly more vigorous than 'Columbia' but did not differ from 'Newport'.

Rhizome disease ratings. There was no significant interaction between location and

Table 2. Plant vigor and disease severity and density ratings in 2016 and 2017 for downy mildew (Pseudoperonospora humuli) foliar symptoms on hop (Humulus lupulus) cultivars.

\begin{tabular}{|c|c|c|c|c|c|c|}
\hline \multirow[b]{2}{*}{ Cultivar } & \multicolumn{2}{|c|}{$\begin{array}{c}\text { Disease severity } \\
\text { (rAUDPC) }\end{array}$} & \multicolumn{2}{|c|}{$\begin{array}{l}\text { Disease density } \\
\text { (rAUDPC) }\end{array}$} & \multicolumn{2}{|c|}{$\begin{array}{l}\text { Mean plant vigor }{ }^{\mathrm{x}} \\
\text { (Shoots/plant) }\end{array}$} \\
\hline & 2016 & 2017 & 2016 & 2017 & PPF (2017) & SWM (2017) \\
\hline Cascade & $0.357 \mathrm{a}^{\mathrm{w}}$ & $0.118 \mathrm{~b}$ & $0.109 \mathrm{a}$ & $0.042 \mathrm{ab}$ & $62.6 \mathrm{a}$ & $50.0 \mathrm{a}$ \\
\hline Nugget & $0.288 \mathrm{abc}$ & $0.169 a b$ & $0.080 \mathrm{a}$ & $0.052 \mathrm{a}$ & $52.3 \mathrm{a}$ & $44.3 \mathrm{ab}$ \\
\hline Triple Pearl & $0.254 \mathrm{bcd}$ & $0.116 \mathrm{~b}$ & $0.043 \mathrm{~b}$ & $0.023 \mathrm{~b}$ & $52.6 \mathrm{a}$ & $55.5 \mathrm{a}$ \\
\hline Comet & $0.227 \mathrm{cde}$ & $0.112 \mathrm{~b}$ & $0.059 \mathrm{ab}$ & $0.048 \mathrm{ab}$ & $28.5 \mathrm{~b}$ & $48.7 \mathrm{ab}$ \\
\hline Newport & $0.191 \mathrm{e}$ & $0.017 \mathrm{c}$ & $0.029 \mathrm{~b}$ & $0.000 \mathrm{~d}$ & $26.3 \mathrm{~b}$ & $44.4 \mathrm{ab}$ \\
\hline Treatment $P$ value & $<0.0001$ & $<0.0001$ & $<0.0001$ & $<0.0001$ & $<0.0001$ & 0.0004 \\
\hline
\end{tabular}

${ }^{\mathrm{z}} \mathrm{rAUDPC}=$ relative area under the disease progress curve. Disease severity $=$ percentage of symptomatic shoots and leaves estimated visually using the Horsfall-Barratt scale converted to midpoint values. Statistical analysis was performed using data from two locations and 2 years as a linear mixed model with unequal variances and repeated measures.

${ }^{\mathrm{y}}$ Disease density $=$ the number of symptomatic downy mildew shoots per plant. Statistical analysis was performed using data from two locations and 2 years as a linear mixed model with unequal variances and repeated measures.

${ }^{\mathrm{x}}$ Plant vigor $=$ the average number of shoots per plant assessed weekly in May and June 2017. Statistical analysis was performed using data from two locations as a linear mixed model with unequal variances. PPF $=$ Michigan State University (MSU) Plant Pathology Farm, Lansing, MI (lat. 42.0835 long. $\left.-86.3542^{\circ}\right)$; SWM $=$ MSU Southwest Michigan Research and Extension Center, Benton Harbor, MI (lat. $42.6854^{\circ}, 1$ long. $-84.4716^{\circ}$ ).

${ }^{\text {w}}$ Least-squared means comparisons were performed using Tukey's adjusted $P$ values $(P=0.05)$. Column means with a letter in common are not significantly different. 
cultivar for CD incidence and severity (Table 3 ), and the main effects for each cultivar were analyzed (Table 4). The CD incidence for 'Centennial' (71.5\%), a cultivar with high foliar disease severity and density, was $35 \%$ to $55 \%$ higher than and significantly different from that of all other cultivars. There were no differences in $\mathrm{CD}$ incidence among cultivars with low foliar disease ratings ('Tahoma', 'Newport', and 'Columbia'). The CD severity data revealed similar trends of the $\mathrm{CD}$ incidence data of 'Centennial' and other cultivars and among cultivars with low foliar disease ratings.

For the VPD incidence, there was a significant interaction between location and cultivar
(Table 3), and the simple effects were analyzed based on cultivar (sliced test results not shown) and location (Table 4). Most cultivars had a significant treatment effect $(P \leq$ 0.0113 ), and the VPD incidence based on cultivar was at least two-times higher for cultivars with significant effects at SWM than those at PFF. 'Centennial' ( $\mathrm{F}=0.41 ; P=0.5277)$ and 'Columbia' ( $\mathrm{F}=3.72 ; P=0.0632$ ) had statistically similar levels of VPD incidence based on cultivar at both locations. Significant treatment effects for VPD incidence were observed based on location at both PPF and SWM (Table 4). At PPF, the VPD incidence of 'Centennial', 'Nugget', and 'Cascade' was significantly higher than that of 'Tahoma', but

Table 3. Mixed model type III test of fixed effects for rhizome size and disease ratings for downy mildew (Pseudoperonospora humuli) symptoms of the rhizome cortex and vascular/pith tissue of hop (Humulus lupulus) cultivars.

\begin{tabular}{|c|c|c|c|c|}
\hline Response variable and effect ${ }^{\mathrm{z}}$ & Num $D^{y}$ & Den $\mathrm{DF}^{\mathrm{x}}$ & F Value & $\operatorname{Pr}>F$ \\
\hline \multicolumn{5}{|l|}{ Wet-rot CD incidence } \\
\hline Location & 1 & 5.52 & 3.21 & 0.1277 \\
\hline Cultivar & 5 & 27.79 & 7.88 & 0.0001 \\
\hline Location $\times$ cultivar & 5 & 27.79 & 1.58 & 0.1988 \\
\hline \multicolumn{5}{|l|}{ Wet-rot CD severity } \\
\hline Location & 1 & 5.12 & 9.38 & 0.0268 \\
\hline Cultivar & 5 & 27.49 & 4.73 & 0.0031 \\
\hline Location $\times$ cultivar & 5 & 27.49 & 1.66 & 0.1769 \\
\hline \multicolumn{5}{|l|}{ VPD incidence } \\
\hline Location & 1 & 5.49 & 16.05 & 0.0085 \\
\hline Cultivar & 5 & 27.67 & 11.37 & $<0.0001$ \\
\hline Location $\times$ cultivar & 5 & 27.67 & 6.62 & 0.0004 \\
\hline \multicolumn{5}{|l|}{ VPD severity } \\
\hline Location & 1 & 5.86 & 16.23 & 0.0072 \\
\hline Cultivar & 5 & 27.92 & 14.88 & $<0.0001$ \\
\hline Location $\times$ cultivar & 5 & 27.92 & 19.77 & $<0.0001$ \\
\hline \multicolumn{5}{|l|}{ Rhizome size } \\
\hline Location & 1 & 11.41 & 2.68 & 0.1290 \\
\hline Cultivar & 5 & 9.64 & 57.01 & $<0.0001$ \\
\hline Location $\times$ cultivar & 5 & 9.64 & 19.05 & 0.0001 \\
\hline
\end{tabular}

${ }^{\mathrm{z}}$ Statistical analysis was performed using data from two locations as a linear mixed model. Unequal variances were specified for the rhizome size response variable. $\mathrm{CD}=$ cortex discoloration and VPD $=$ vascular and pith discoloration.

${ }^{\mathrm{y}} \mathrm{Num} \mathrm{DF}=$ Numerator $\mathrm{df}$.

${ }^{\mathrm{x}}$ Den DF $=$ Denominator $\mathrm{df}$. it did not differ from that of the other cultivars. Among cultivars with low foliar disease ratings, 'Newport' and 'Columbia' had a significantly higher incidence than 'Tahoma' (PPF). At SWM, the VPD incidence of 'Centennial', 'Nugget', and 'Cascade' was significantly higher than that of 'Tahoma' and 'Columbia'. 'Nugget' surpassed 'Centennial' as having the highest VPD incidence (SWM), but it did not differ statistically from 'Cascade'. Among cultivars with a low foliar disease rating, only 'Newport' had a higher VPD incidence than 'Tahoma' (SWM).

For VPD severity, there was a significant interaction between location and cultivar ( $\mathrm{Ta}-$ ble 3 ), and the simple effects were analyzed based on cultivar (sliced test results not shown) and location (Table 4). Most cultivars had a significant treatment effect $(P \leq$ 0.026), and VPD incidence based on cultivar was at least two-times higher for cultivars, with significant effects at SWM than at PFF. 'Centennial' $(\mathrm{F}=0.01 ; P=0.9180)$ and 'Columbia' ( $\mathrm{F}=2.77 ; P=0.1137)$ had statistically similar levels of VPD incidence based on cultivar at both locations. Significant treatment effects for VPD severity were observed based on location at both PPF and SWM (Table 4). At PPF, VPD severity was less than 13\%. For 'Centennial', 'Nugget', and 'Cascade', the VPD severity was significantly higher than that of 'Tahoma' $(1.2 \%)$, but it did not differ from that of the other cultivars. Trends for VPD severity (PPF) among cultivars with low foliar disease ratings were similar to those of VPD incidence at the same location. At SWM, the VPD severity for 'Centennial' was low (12.0\%), did not differ from that 'Tahoma', and had lower severity than that of 'Newport'. 'Nugget' was among the cultivars with high foliar disease ratings and had more severe VPD symptoms $(57.8 \%)$ than any other cultivar (SWM). Among cultivars with low foliar disease rat-

Table 4. Downy mildew (Pseudoperonospora humuli) rhizome symptoms and rhizome size in 2018 for hop (Humulus lupulus) cultivars.

\begin{tabular}{|c|c|c|c|c|c|c|c|c|}
\hline \multirow[b]{3}{*}{ Cultivar } & & & \multicolumn{4}{|c|}{$\mathrm{VPD}^{\mathrm{y}}$} & & \\
\hline & \multicolumn{2}{|c|}{ Wet-rot $\mathrm{CD}^{\mathrm{z}}$} & \multicolumn{2}{|c|}{$\mathrm{PPF}^{\mathrm{w}}$} & \multicolumn{2}{|c|}{ SWM } & \multicolumn{2}{|c|}{ Rhizome size ${ }^{\mathrm{x}}$} \\
\hline & Incidence $^{\mathrm{v}}$ & Severity & Incidence & Severity & Incidence & Severity & PPF & SWM \\
\hline$\overline{\text { Centennial }}$ & $71.5 \mathrm{a}$ & $31.9 \mathrm{a}$ & $47.8 \mathrm{a}$ & $12.4 \mathrm{a}$ & $56.2 \mathrm{~b}$ & $12.0 \mathrm{c}$ & $10.7 \mathrm{ab}$ & $10.0 \mathrm{a}$ \\
\hline Nugget & $33.7 \mathrm{~b}$ & $8.1 \mathrm{~b}$ & $32.5 \mathrm{a}$ & $4.4 \mathrm{~b}$ & $98.0 \mathrm{a}$ & $57.8 \mathrm{a}$ & $9.9 \mathrm{~b}$ & $10.9 \mathrm{a}$ \\
\hline Cascade & $32.3 \mathrm{~b}$ & $6.7 \mathrm{~b}$ & $30.2 \mathrm{a}$ & $4.9 \mathrm{~b}$ & $74.8 \mathrm{ab}$ & $28.0 \mathrm{~b}$ & $8.1 \mathrm{~b}$ & $8.3 \mathrm{~b}$ \\
\hline Columbia & $47.2 \mathrm{~b}$ & $17.7 \mathrm{~b}$ & $32.4 \mathrm{a}$ & $8.9 \mathrm{ab}$ & $17.5 \mathrm{c}$ & $3.8 \mathrm{~d}$ & $11.8 \mathrm{a}$ & $9.9 \mathrm{a}$ \\
\hline Newport & $38.5 \mathrm{~b}$ & $13.9 \mathrm{~b}$ & $32.6 \mathrm{a}$ & $9.0 \mathrm{ab}$ & $62.2 \mathrm{~b}$ & $20.4 \mathrm{~b}$ & $10.9 \mathrm{ab}$ & $9.8 \mathrm{ab}$ \\
\hline Tahoma & $46.4 \mathrm{~b}$ & $12.5 \mathrm{~b}$ & $11.9 \mathrm{~b}$ & $1.2 \mathrm{c}$ & $32.1 \mathrm{c}$ & $9.8 \mathrm{c}$ & $9.3 \mathrm{~b}$ & $7.2 \mathrm{c}$ \\
\hline Treatment $P$ value & 0.0001 & 0.0031 & 0.0034 & 0.0003 & $<0.0001$ & $<0.0001$ & $<0.0001$ & $<0.0001$ \\
\hline
\end{tabular}

${ }^{\mathrm{z}} \mathrm{CD}=$ cortex discoloration. Statistical analysis was performed using data from two locations as a linear mixed model. There was no interaction between location and cultivar for cortex incidence $(\mathrm{F}=1.61 ; P=0.1904)$ and severity $(\mathrm{F}=1.66 ; P=0.1769)$.

${ }^{\mathrm{y}} \mathrm{VPD}=$ vascular/pith discoloration. VPD occurred as slightly water-soaked, red-brown, flecking, and streaking. Statistical analysis performed using data from two locations as a linear mixed model. Significant interaction was observed between location and cultivar for vascular/pith discoloration incidence $(\mathrm{F}=$ 6.62; $P=0.0004)$ and severity $(\mathrm{F}=19.77 ; P<0.0001)$.

${ }^{\mathrm{x}}$ Rhizome size $=$ diameter of rhizome $(\mathrm{mm})$. Statistical analysis was performed using data from two locations as a linear mixed model with unequal variances. Significant interaction was observed between location and cultivar for rhizome size $(\mathrm{F}=19.05 ; P=0.0001)$.

${ }^{\mathrm{w}} \mathrm{PPF}=$ Michigan State University (MSU) Plant Pathology Farm, Lansing, MI (lat. 42.0835 , long. $-86.3542^{\circ}$ ); SWM = Michigan State University (MSU) Southwest Michigan Research and Extension Center, Benton Harbor, MI (lat. $42.6854^{\circ}$, long. $-84.4716^{\circ}$ ).

${ }^{\mathrm{v}}$ Disease incidence $=$ the number of rhizomes with symptoms. Disease severity $=$ direct estimate $(0 \%$ to $100 \%)$ with the aid of a disease diagram of the portion of cortex or vascular/pith tissue covered with downy mildew symptoms. Fisher's protected least significant differences at $P<0.05$ were used to make comparisons of least-squared means of fungicides. Column means with a letter in common are not significantly different. 
ings, 'Newport' had the highest severity (statistically similar to that of 'Cascade'). 'Tahoma' and 'Columbia' had less than 10\% severity (SWM).

There was a significant interaction between location and cultivar for rhizome size (Table 3), and the simple effects were analyzed based on cultivar (sliced test results not shown) and location (Table 4). Most cultivars did not have a significant treatment effect and rhizome size based on cultivar was similar at both locations; 'Colombia' ( $\mathrm{F}=10.19 ; P=$ $0.0077)$ and 'Tahoma' ( $\mathrm{F}=40.62 ; P=$ 0.0007) had larger diameters at PPF than SWM. Significant treatment effects for rhizome size were observed based on location at both PPF and SWM (Table 4). At PPF, the 'Centennial' rhizome size was similar to that of other cultivars with less wet-rot CD. At SWM, 'Centennial' had a larger rhizome diameter than some cultivars with less wet-rot CD ('Cascade' and 'Tahoma'), but it was similar to that of most other cultivars.

Significant positive correlations were observed between symptom incidence and severity for $\mathrm{CD}$ and VPD (Table 5). The diameter size of rhizomes was positively correlated with $C D$ incidence and severity. No correlations were observed between VPD symptoms and rhizome size.

\section{Discussion}

Field assessments of DM susceptibility are complicated by crown rot symptoms hidden belowground (Neve, 1991; Woods and Gent, 2016). It is difficult to determine whether low vigor cultivars are a result of susceptibility to rootstock rot or poor adaptation to their environment. This study combined foliar DM disease ratings (symptomatic shoots and symptomatic shoot plus localized leaf lesions) with an assessment of belowground DM symptoms to determine cultivar susceptibility to rootstock rot regardless of plant vigor. 'Centennial', 'Nugget', and 'Cascade' consistently had more severe foliar symptoms than 'Columbia', 'Tahoma', and 'Newport', and the rhizomes of these cultivars were used for the assessment of rootstock rot. Only 'Centennial' had more wetrot $\mathrm{CD}$ in its rhizomes compared to the other cultivars.

Table 5. Pearson's correlation coefficients among rhizome size and downy mildew (Pseudoperonospora humuli) symptoms of the rhizomes of hop (Humulus lupulus) cultivars.

\begin{tabular}{lccccc}
\hline & $\mathrm{CD}^{\mathrm{z}}$ incidence & $\mathrm{CD}$ severity & $\mathrm{VPD}^{\mathrm{y}}$ incidence & VPD severity & Diam $^{\mathrm{x}}$ \\
\hline CD incidence & $1.000^{\mathrm{w}}$ & & & & \\
CD severity & $0.855^{* *}$ & 1.000 & & & \\
VPD incidence & 0.132 & 0.257 & 1.000 & & \\
VPD severity & 0.131 & 0.132 & $0.748^{* *}$ & 1.000 & \\
Diameter & $0.403^{*}$ & $0.439^{*}$ & 0.125 & 0.038 & 1.000 \\
\hline
\end{tabular}

${ }^{\mathrm{z}} \mathrm{CD}=$ Wet-rot cortex discoloration.

${ }^{\mathrm{y}} \mathrm{VPD}=$ Slightly water-soaked vascular/pith discoloration often occurring as red-brown, flecking, and streaking.

${ }^{\mathrm{x}}$ Diameter $=$ rhizome diameter.

${ }^{\mathrm{w}}$ Disease incidence $=$ the number of rhizomes with symptoms. Disease severity $=$ direct estimate $(0 \%$ to $100 \%)$ with the aid of a disease diagram of the portion of cortex or vascular/pith tissue covered with downy mildew symptoms. ${ }^{*}$ and $* *$ indicate value is statistically significant at $P<0.01$ and 0.0001 , respectively. $\mathrm{N}=46$. comparable to that of 'Tahoma', a cultivar that displayed higher vigor and similarly low levels of foliar disease. 'Newport' was noted for a lack of DM symptoms during breeding trials in Oregon and Washington (Henning et al., 2004) and has a parental heritage of European origin ['Hallertauer Magnum' (Henning et al., 2004)] that is linked to DM resistance (Woods and Gent, 2016). 'Tahoma' is an aroma hop with limited information regarding DM susceptibility; however, here, it demonstrated low foliar disease levels and lower wet-rot CD than highly susceptible 'Centennial'.

The level of wet-rot $C D$ for cultivars with low foliar disease ratings ('Tahoma', 'Newport', and 'Columbia') was comparable to that of some cultivars with more severe foliar disease symptoms (e.g., 'Nugget' and 'Cascade'). Reduced foliar disease symptoms of hop cultivars displaying similar levels of rootstock rot suggest that a defense mechanism may be limiting foliar DM symptoms. One possibility is that all rootstock is susceptible to infection by $P$. humuli, but that cultivars with reduced shoot symptoms are resistant to systemic colonization. In Plasmopara halstedii, all pathogen races can infect sunflower roots, but systemic growth up the hypocotyl and colonization of the cotyledon is governed by compatible pathogen-host interactions, and the extent of colonization results in two distinct resistant phenotypes (Mouzeyar et al., 1993, 1994; Radwan et al., 2011). The formation of tyloses, as seen in interactions between Verticillium nonalfalfae and hop, can limit colonization of the vascular system (Talboys, 1958). Defense responses observed in other host-DM pathogen interactions, such as a hypersensitive reaction in the parenchyma (Mouzeyar et al., 1993), callose-like and lignin-like encasement of hyphae and haustoria (Cohen et al., 1989), lignification and peroxidase activity in the parenchyma (Asada and Matsumoto, 1969; Ohguchi and Asada, 1975), or an accumulation of salicylic acid in the vascular system (Yan et al., 2020), may act to limit systemic colonization. Although no cultivar-specific races of $P$. humuli have been reported, studies to determine race (Hoerner, 1940) and reports of quantitative resistance (Henning et al., 2015) have been conducted with leaf inoculations or are focused on foliar infection. These studies have not assessed resistance reactions or colonization of belowground plant tissue. Despite limited overall genetic diversity, a dominant genotype can systemically establish in hop rootstock on a single cultivar in hop yards or plants of close proximity (Gent et al., 2019). A comparison between cultivars with varying rootstock responses would be helpful to determine if distinct genotypes exist by cultivar. In addition to the host range, race can also be distinguished by virulence and symptom expression (D'Arcy et al., 2001). Screening for compatibility with $P$. humuli isolates and characterizing defense responses of rootstock may help explain differences in susceptibility to basal shoot colonization of hop cultivars with similar tolerance or intermediate resistance to rootstock rot. 
In this study, there was a significant positive correlation between rhizome size and the wet-rot CD disease ratings. During ontogenesis, rhizomes produce a 2 - to 6-mm ring of annual growth (Rybaček, 1991). The average diameter of rhizomes $(>7 \mathrm{~mm})$ of all cultivars indicated that most of the rhizomes sampled were older than 1 year. As a rhizome reaches maturity, typically in year four, there is an increasing rate of tissue death (Rybaček, 1991), which may, in part, explain the strong positive correlation between rhizome size and wet-rot $\mathrm{CD}$. Yet, there are physiological and biochemical differences between young (1 year or less) and old rhizomes (Rybaček, 1991) that may increase disease susceptibility as rhizomes mature. For instance, total monosaccharides decrease $200 \%$ in young compared with older rhizomes (Rybaček, 1991). The rare sugar monosaccharide D-tagatose can disrupt the mannose metabolism of $\mathrm{Hya}$ loperonospora arabidopsidis and appears to have fungicidal effects on $P$. cubensis (Mochizuki et al., 2020). Moreover, D-tagatose was found in root exudates of maize seedlings (Canellas et al., 2019).

It should be noted that wet-rot CD in hop rootstock is also caused by Phytophthora spp. (Brien, 1938; Royle, 1968; Sonoda and Ogawa, 1968) and may confound cultivar comparisons based on rot symptoms. There is limited information about cultivar susceptibility to Phytophthora spp., and black root rot is largely unreported in the United States. A molecular diagnostic tool would be helpful to distinguish wet-rot CD symptoms caused by the two pathogens. Yet, current molecular diagnostic assays for P. humuli (Gent et al., 2009; Patzak, 2005; Rahman et al., 2019; Summers et al., 2015) have not been validated in rootstock tissue that may contain polymerase chain reaction inhibitors leading to a false-negative diagnosis (Gao et al., 2004). Furthermore, the Phytophthora genus-specific atp9-nad9 marker system (Bilodeau et al., 2014; Miles et al., 2017) lacks specificity and off-target detection occurs with $P$. humuli (Higgins et al., unpublished data). Additional work to validate molecular diagnostic markers would be an important next step to understand the wet-rot CD response of hop cultivars.

The VPD symptoms did not always follow a clear pattern among cultivars. 'Centennial', in which we might expect the highest VPD incidence and severity, did not separate from the others and differences among cultivars varied by location. For the most part, VPD of 'Tahoma' was lower than that of 'Centennial'; however, VPD severity at SWM was an exception. Although Henning et al. (2016) did not find differences in foliar symptoms between locations in the $\mathrm{Pa}$ cific Northwest, quantitative resistance can vary under certain environmental conditions (Pilet-Nayel et al., 2017). Because of differences in VPD ratings between locations in this experiment and climatic conditions in the eastern United States compared with the $\mathrm{Pa}$ cific Northwest, we recommend site-specific evaluations for other production regions.
We observed a range of symptom colors, reddish brown, dark brown, or black, for both $\mathrm{CD}$ and VPD. Previous studies considered the darkening of symptoms to represent the progression of the disease (Coley-Smith, 1962; Skotland, 1961). Coley-Smith (1964) noted that in DM-infected rhizomes, large areas of wet-rot discoloration in the cortex were more common than the flecking symptom, but that during latter stages of infection, both symptoms may occur throughout all tissue types. We devised our rating scale to distinguish between the two distinct regions, cortex or vascular/pith tissue, where symptoms occurred. Differences in the locations of DM symptoms may be linked to varying defense responses among cultivars or differences in the initial site of infection. For 'Nugget', 'Cascade', and 'Newport' at SWM, the VPD incidence was higher than the CD incidence. VPD, at times, appeared in the pith tissue, with a distinct boundary between symptomatic and asymptomatic tissue. Pith symptoms might be caused by natural decay (Rybaček, 1991); however, there was no significant correlation between rhizome size and either VPD disease rating. Phomopsis tuberivora (H.T. Güssow \& W.R. Foster) B. Sutton 1980, the causal agent of red crown rot of hop, produces a similar set of pith symptoms (Gent et al., 2013). VPD caused by other pathogens could not be ruled out during this study and may explain, in part, the higher VPD incidence of some cultivars.

The high vigor and low foliar symptom responses of 'Tahoma' in this study are similar to those of other cultivars that are classified as tolerant to rootstock rot and basal shoot infection (Woods and Gent, 2016). Contrary to expectations, vigor did not differ between 'Tahoma' and 'Centennial', despite the significant difference in wet-rot $C D$ susceptibility. Differences in vigor caused by DM rootstock rot may be difficult to detect during short-term studies, and vigor ratings in general may be confounded by other factors. Woods and Gent (2016) worked with cultivars established over a 25 -year period and then left for 7 years without the protection of fungicide (minimum age of 8 years based on the last assessment date), resulting in ample time to observe the effects of rootstock rot on plant vigor. Conversely, commercial hop yards are typically only productive for 10 to 20 years (Beatson et al., 2009), and long-term studies must contend with a natural decline in vigor in older cultivars

Understanding the differences in hop cultivar susceptibility has value for both breeders and growers. Highly desired brewing characteristic may continue to drive the planting of DM-susceptible cultivars. The desirable cultivars susceptible to rootstock rot and those that tolerate root rot but still produce foliar symptoms will require the protection of fungicides. The research presented here highlights the need to explain the differences in susceptibility to basal shoot infections of hop cultivars with similar tolerances to rootstock rot to aid future breeding efforts.

\section{Literature Cited}

Asada, Y. and I. Matsumoto. 1969. Formation of lignin-like substance in the root tissues of Japanese radish plant infected by downy mildew fungus. Japn. J. Phyto. 35:160-167, doi: 10.3186/jjphytopath.35.160.

Beatson, R., S. Kenny, S. Pethybridge, and D. Gent. 2009. Hop production, p. 5-8. In: W.F. Mahaffee, S.J. Pethybridge, and D.H. Gent (eds.). Compendium of hop diseases and pests. APS Press, St. Paul, MN.

Bilodeau, G.J., F.N. Martin, M.D. Coffey, and C.L. Blomquist. 2014. Development of a multiplex assay for genus- and species-specific detection of Phytophthora based on differences in mitochondrial gene order. Phytopathology 104: 733-748, doi: 10.1094/phyto-09-13-0263-r.

Box, G.E. and D.R. Cox. 1964. An analysis of transformations. J. R. Stat. Soc. Series B Stat. Methodol. 26:211-243.

Brien, R. 1938. Black root-rot of hops. New Zealand Department of Scientific and Industrial Research, Plant Disease Division Bulletin no. 11.

Brooks, S., C. Horner, S. Likens, and C. Zimmermann. 1972. Registration of Cascade Hop1 (reg. no. 1). Crop Sci. 12:394-394, doi: 10.2135/cropsci1972.0011183x001200030044x.

Canellas, L.P., F.L. Olivares, N.O. Canellas, P. Mazzei, and A. Piccolo. 2019. Humic acids increase the maize seedlings exudation yield. Chem. Biol. Technol. Agr. 6:3, doi: 10.1186/ s40538-018-0139-7.

Cohen, Y., H. Eyal, J. Hanania, and Z. Malik. 1989. Ultrastructure of Pseudoperonospora $\mathrm{cu}$ bensis in muskmelon genotypes susceptible and resistant to downy mildew. Physiol. Mol. Plant Pathol. 34:27-40, doi: 10.1016/0885-5765(89) 90014-3.

Coley-Smith, J.R. 1962. Overwintering of hop downy mildew Pseudoperonospora humuli (Miy. and Tak.). Wilson. Ann. Appl. Biol. 50:235-243, doi: 10.1111/j.1744-7348.1962.tb06006.x.

Coley-Smith, J.R. 1965. Infection of hop rootstocks by downy mildew Pseudoperonospora humuli (Miy. \& Tak.) Wilson and its control by earlyseason dusts. Ann. Appl. Biol. 56:381-388, doi: 10.1111/j.1744-7348.1965.tb01256.x.

Coley-Smith, J.R. 1964. Persistence and identification of downy mildew Pseudoperonospora humuli (Miy. and Tak.) Wilson in hop rootstocks. Ann. Appl. Biol. 53:129-132, doi: 10.1111/ j.1744-7348.1964.tb03786.x.

D'Arcy, C.J., D.M. Eastburn, and G.L. Schumann. 2001. Illustrated glossary of plant pathology. The plant health instructor, doi: 10.1094/PHI-I2001-0219-01.

Gao, X., T. Jackson, K.N. Lambert, S. Li, G.L. Hartman, and T. Niblack. 2004. Detection and quantification of Fusarium solani f. sp. glycines in soybean roots with real-time quantitative polymerase chain reaction. Plant Dis. 88:13721380, doi: 10.1094/pdis.2004.88.12.1372.

Gent, D.H., N. Adair, B.J. Knaus, and N.J. Grünwald. 2019. Genotyping-by-sequencing reveals fine-scale differentiation in populations of Pseudoperonospora humuli. Phytopathology 109: 1801-1810, doi: 10.1094/phyto-12-18-0485-r.

Gent, D.H., J.L. Farnsworth, and D.A. Johnson. 2012. Spatial analysis and incidence-density relationships for downy mildew on hop. Plant Pathol. 61: 37-47, doi: 10.1111/j.1365-3059.2011.02491.x.

Gent, D.H., G. Mueller-Warrant, J.L. Woods, M.L. Putnam, and M.C. Twomey. 2013. Red crown rot of hop in Oregon caused by Phomopsis tuberivora. Plant Health Prog. 14:52, doi: 10.1094/php-2013-0624-01-br.

Gent, D.H., M.E. Nelson, and G.G. Grove. 2008. Persistence of phenylamide insensitivity in 
Pseudoperonospora humuli. Plant Dis. 92:463468, doi: 10.1094/pdis-92-3-0463.

Gent, D.H., M.E. Nelson, J.L. Farnsworth, and G.G. Grove. 2009. PCR detection of Pseudoperonospora humuli in air samples from hop yards. Plant Pathol. 58:1081-1091, doi: 10.1111/j.1365-3059.2009.02143.x.

George, A. 2020. USA hops 2019 statistical report. Hop Growers of America, Online publication: usahops.org.

Haunold, A., S. Likens, C. Horner, C. Zimmermann, and D. Roberts. 1976. Registration of Columbia Hop1 (reg. no. 5). Crop Sci. 16:738-739, doi: $.2135 /$ cropsci1976.0011183x001600050042x.

Haunold, A., S. Likens, G. Nickerson, and R. Hampton. 1984. Registration of Nugget hop. Crop Sci. 24 : 618, doi: 10.2135/cropsci1984.0011183X00240 0030046x.

Henning, J., S. Townsend, W. Mahaffee, S. Kenny, and A. Haunold. 2004. Registration of 'Newport' hop. Crop Sci. 44:1018-1019, doi: 10.2135/cropsci2004.1018a.

Henning, J.A., D. Gent, M.S. Townsend, and A Haunold. 2018. Registration of downy mildew-resistant male hop germplasm USDA 21087M. J. Plant Regist. 12:379-381, doi: 10.3198/jpr2017.09.0067 crg.

Henning, J.A., D.H. Gent, M.C. Twomey, M.S. Townsend, N.J. Pitra, and P.D. Matthews. 2015. Precision QTL mapping of downy mildew resistance in hop (Humulus lupulus L.). Euphytica 202:487-498, doi: 10.1007/s10681015-1356-9.

Henning, J.A., D.H. Gent, M.C. Twomey, M.S Townsend, N.J. Pitra, and P.D. Matthews. 2016. Genotyping-by-sequencing of a bi-parental mapping population segregating for downy mildew resistance in hop (Humulus lupulus $\mathrm{L}$.). Euphytica 208:545-559, doi: 10.1007/s10681015-1600-3.

Higgins, D.S. and M.K. Hausbeck. 2017. Fungicides and cultivars can limit hop downy mildew (Pseudoperonospora humuli) in Michigan. Phytopathology 107(12S):S5-S78.

Higgins, D.S. and M.K. Hausbeck. 2018. Effective management strategies for hop downy mildew (Pseudoperonospora humuli) in Michigan. Phytopathology. 108(12S):S2.28.

Hoerner, G. 1940. The infection capabilities of hop downy mildew. J. Agr. Res. 61:331-334.

Horsfall, J.G. and R.W. Barratt. 1945. An improved grading system for measuring plant diseases. Phytopathology 35:655.

Johnson, D. and W. Anliker. 1985. Effect of downy mildew epidemics on the seasonal carryover of initial inoculum in hop yards. Plant Dis. 69:140-142, doi: 10.1094/pd-69-140.

Johnson, D.A. and C. Skotland. 1985. Effects of temperature and relative humidity on sporangium production of Pseudoperonospora humuli on hop. Phytopathology 75:127-129, doi: 10.1094/phyto-75-127.

Kenny, S. and C. Zimmermann. 1991. Registration of 'Centennial'. Hop. Crop Sci. 31:1092, doi: 10.2135/cropsci1991.0011183x003100040063x.

Madden, L.V., G. Hughes, and F. van den Bosch. 2007. The study of plant disease epidemics. American Phytopathological Society, St. Paul, MN.

Mahaffee, W.F., S.J. Pethybridge, and D.H. Gent. 2009. Compendium of hop diseases and pests. American Phytopathological Society (APS Press), St. Paul, MN.
Miles, T.D., F.N. Martin, G.P. Robideau, G.J. Bilodeau, and M.D. Coffey. 2017. Systematic development of Phytophthora species-specific mitochondrial diagnostic markers for economically important members of the genus. Plant Dis. 101:1162-1170, doi: 10.1094/pdis-0916-1224-re.

Mochizuki, S., T. Fukumoto, T. Ohara, K. Ohtani, A. Yoshihara, Y. Shigematsu, K. Tanaka, K. Ebihara, S. Tajima, and K. Gomi. 2020. The rare sugar d-tagatose protects plants from downy mildews and is a safe fungicidal agrochemical. Commun. Biol. 3:1-15, doi: 10.1038/s42003020-01133-7.

Mouzeyar, S., D.T. De Labrouhe, and F. Vear. 1993. Histopathological studies of resistance of sunflower (Helianthus annuus L.) to downy mildew (Plasmopara halstedii). J. Phytopathol. 139:289-297, doi: 10.1111/j.1439-0434.1993. tb01430.x.

Mouzeyar, S., D.T. De Labrouhe, and F. Vear. 1994. Effect of host-race combination on resistance of sunflower, Helianthus annuus L., to downy mildew Plasmopara balstedii. J. Phytopathol. 141:249-258, doi: 10.1111/j.1439-0434. 1994.tb01468.x.

Nelson, M.E. and G.G. Grove. 2004. Evaluation of fungcides for control of hop downy mildew, 2003. Fungic. Nematic. Tests 59:FC017.

Neve, R.A. 1991. Hops. Springer, Berlin, Germany.

O'Neal, S. 2015. Pest management strategic plan for U.S. hops: Summary of a workshop held on Nov. 4, 2014, Yakima, WA. Washington State University Irrigated Agriculture Research and Extension Center. <https://ipmdata.ipmcenters.org/ documents/pmsps/US-hops-PMSP2015.pdf $>$.

Ohguchi, T. and Y. Asada. 1975. Dehydrogenation polymerization products of p-hydroxycinnamyl alcohols by isoperoxidases obtained from downy mildew-infected roots of Japanese radish (Raphanus sativus). Physiol. Plant Pathol. 5: 183-192, doi: 10.1016/0048-4059(75)90020-x.

Pagán, I. and F. García-Arenal. 2020. Tolerance of plants to pathogens: A unifying view. Annu. Rev. Phytopathol. 58:77-96, doi: 10.1146/annurev-phyto-010820-012749.

Patzak, J. 2005. PCR detection of Pseudoperonospora humuli and Podosphaera macularis (Humulus lupulus). Plant Prot. Sci. 41:141-149, doi: 10.17221/2749-pps.

Pilet-Nayel, M.L., B. Moury, V. Caffier, J. Montarry, M.C. Kerlan, S. Fournet, C.E. Durel, and R. Delourme. 2017. Quantitative resistance to plant pathogens in pyramiding strategies for durable crop protection. Front. Plant Sci. 8: 1838, doi: 10.3389/fpls.2017.01838.

Radwan, O., M.F. Bouzidi, and S. Mouzeyar. 2011. Molecular characterization of two types of resistance in sunflower to Plasmopara halstedii, the causal agent of downy mildew. Phytopathology 101:970-979, doi: 10.1094/phyto-06-10-0163.

Rahman, A., E. Gongora-Castillo, M.J. Bowman, K.L. Childs, D.H. Gent, F.N. Martin, and L.M. Quesada-Ocampo. 2019. Genome sequencing and transcriptome analysis of the hop downy mildew pathogen Pseudoperonospora humuli reveal species-specific genes for molecular detection. Phytopathology 109:1354-1366, doi: 10.1094/phyto-11-18-0431-r.

Royle, D. 1968. Hop black root-rot (Phytophthra citricola Sawada) in England. Plant Pathol. 17:3640, doi: 10.1111/j.1365-3059.1968.tb00413.x.
Royle, D. and H.T. Kremheller. 1981. Downy mildew of the hop. In: D.M. Spencer (ed.). The downy mildews. Academic Press Inc., New York, NY.

Royle, D. and G. Thomas. 1971a. The influence of stomatal opening on the infection of hop leaves by Pseudoperonospora humuli. Physiol. Plant Pathol. 1:329-343, doi: 10.1016/0048-4059(71) 90053-1.

Royle, D. and G. Thomas. 1971b. Observations with the scanning electron microscope on the early stages of hop leaf infection by Pseudoperonospora humuli. Physiol. Plant Pathol. 1: 345-349, doi: 10.1016/0048-4059(71)90054-3.

Royle, D. and G. Thomas. 1973. Factors affecting zoospore responses towards stomata in hop downy mildew (Pseudoperonospora humuli) including some comparisons with grapevine downy mildew (Plasmopara viticola). Physiol. Plant Pathol. 3:405-417, doi: 10.1016/00484059(73)90013-1.

Royle, D.J. 1970. Infection periods in relation to the natural development of hop downy mildew (Pseudoperonospora humuli). Ann. Appl. Biol. 66:281291, doi: 10.1111/j.1744-7348.1970.tb06435.x.

Rybaček, V. 1991. Hop production. Elsevier, New York, NY.

Skotland, C. 1961. Infection of hop crowns and roots by Pseudoperonospora humuli and its relation to crown and root rot and overwintering of the pathogen. Phytopathology 51:241-244.

Sonoda, R. and J. Ogawa. 1968. Phytophthora crown and root rot of hops in California. Plant Dis. Rep. 52:76-78.

Sonoda, R. and J. Ogawa. 1972. Ecological factors limiting epidemics of hop downy mildew in arid climates. Hilgardia 41:457-473, doi: 10.3733/hilg.v41n15p457.

Summers, C.F., N.L. Adair, D.H. Gent, M.T McGrath, and C.D. Smart. 2015. Pseudoperonospora cubensis and $P$. humuli detection using species-specific probes and high definition melt curve analysis. Can. J. Plant Pathol. 37:315-330, doi: 10.1080/07060661.2015.1053989.

Talboys, P. 1958. Association of tylosis and hyperplasia of the xylem with vascular invasion of the hop by Verticillium albo-atrum. Trans. Br. Mycol. Soc. 41:249-260, doi: 10.1016/s00071536(58)80037-6.

Ware, W. 1926. Pseudoperonospora humuli and its mycelial invasion of the host plant. Trans. Br. Mycol. Soc. 11:91-107, doi: 10.1016/s00071536(26)80029-4.

Williams, I.H., J.B. Roberts, and J.R. Coley-Smith 1961. Studies of the dormant phase of the hop (Humulus lupulus L.). Rep. Dept. Hop Res. Wye Coll. 1960:48-58.

Woods, J.L. and D.H. Gent. 2016. Susceptibility of hop cultivars to downy mildew: Associations with chemical characteristics and region of origin. Plant Health Prog. 17:42-48, doi: 10.1094/ php-rs-15-0044.

Yan, S., K. Ning, Z. Wang, X. Liu, Y. Zhong, L. Ding, H. Zi, Z. Cheng, X. Li, and H. Shan. 2020. CsIVP functions in vasculature development and downy mildew resistance in cucumber. PLoS Biol. 18:e3000671, doi: 10.1371/ journal.pbio.3000671.

Zimmermann, C., S. Likens, A. Haunold, C. Horner, and D. Roberts. 1975. Registration of Comet Hop 1 (reg. no. 3). Crop Sci. 15:98, doi: 10.2135/cropsci1975.0011183x001500010035x. 